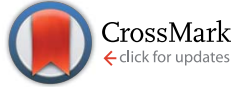

Cite this: J. Mater. Chem. A, 2017, 5, 11644

Received 7th December 2016

Accepted 5th January 2017

DOI: $10.1039 / c 6 t a 10517 c$

www.rsc.org/MaterialsA

\section{Mechanistic insights into the formation of porous carbons from gelatin $\uparrow$}

\author{
A. E. Danks, ${ }^{a}$ M. J. Hollamby, ${ }^{\text {b }}$ B. Hammouda, ${ }^{c}$ D. C. Fletcher, ${ }^{a}$ F. Johnston-Banks, ${ }^{d}$ \\ S. E. Rogers ${ }^{e}$ and Z. Schnepp ${ }^{\star a}$
}

Porous carbons are important for many energy applications. The biopolymer gelatin provides a simple and sustainable route to functional carbon foams with multimodal porosity. In this paper, small angle neutron scattering is applied alongside other techniques to elucidate the mechanism of formation of these foams. Analysis of the data demonstrates that combinations of different metal nitrates can be used to control foam macrostructure. Synergistic interaction of metal ions with the gelatin polypeptide changes the viscoelastic properties and thus controls foam formation.

\section{Introduction}

Materials for energy applications require increasing levels of chemical and structural complexity. For example, catalysts benefit from porosity on multiple length scales for a high accessible surface area., ${ }^{1,2}$ Materials for light harvesting may require semiconductor and cocatalyst nanostructures as well as a high surface area to maximise conversion efficiency. ${ }^{3}$ One way to introduce complexity in a simple way is to harness biological structures. These can take the form of raw biomass, which is generally used as a template to impart structural complexity either by coating or infilling with a desired material. ${ }^{4}$ Alternatively, biological polymers (biopolymers) can be used to synthesize nanostructures in solution, ${ }^{5}$ or to provide structural control in the high temperature sol-gel synthesis of metal oxides, carbides or nitrides. ${ }^{6}$

Biopolymers are particularly well suited to the control of micro and macrostructure in materials synthesis due to their high thermal stability. In addition, many biopolymers selfassemble into gels or fibres, which can be used to direct the growth of an inorganic material. In most of these cases, the biopolymer provides a matrix that 'traps' metal ions in an aqueous gel. ${ }^{7}$ This matrix can be used as a precursor for sol-gel synthesis of various materials. For example, the seaweed biopolymer alginate binds strongly to multivalent metal ions to form gels with organized crystal-like regions. This effect has been used to synthesize nanowires of materials such as

${ }^{a}$ School of Chemistry, University of Birmingham, B15 2TT, UK. E-mail: z.schnepp@ bham.ac.uk

${ }^{b}$ School of Chemical and Physical Sciences, Keele University, ST5 5BG, UK

${ }^{c}$ NIST, 100 Bureau Drive, Gaithersburg, MD, 20899, USA

${ }^{d}$ Healan Ingredients Ltd, Market Weighton, York, YO43 3AZ, UK

${ }^{e}$ ISIS Neutron and Muon Source, Didcot, OX11 OQX, UK

$\dagger$ Electronic supplementary information (ESI) available. See DOI: $10.1039 / \mathrm{c} 6 \mathrm{ta} 10517 \mathrm{c}$
$\mathrm{YBa}_{2} \mathrm{Cu}_{4} \mathrm{O}_{8}$ (ref. 8) or $\mathrm{La}_{0.67} \mathrm{Sr}_{0.33} \mathrm{MnO}_{3}$ (ref. 9) through organization of aqueous metal ions in an alginate matrix and subsequent heating to produce the ceramic.

Recently, the biopolymer gelatin was used in conjunction with metal nitrate salts to produce a wide range of carbon foams with embedded metal oxide, nitride or carbide nanoparticles. ${ }^{10}$ These can either be used directly as catalysts e.g. in methanol reforming, ${ }^{11}$ or etched with dilute acid to produce carbons with multimodal porosity with applications in electrocatalysis. ${ }^{12}$ The latter example was produced by mixing iron and magnesium nitrates with gelatin and heating under nitrogen to form a foam with $\mathrm{MgO}$ and $\mathrm{Fe}_{3} \mathrm{C}$ nanoparticles (Fig. 1a). Etching the $\mathrm{MgO}$ $(<2 \mathrm{~nm}$ diameter $)$ and $\mathrm{Fe}_{3} \mathrm{C}(\sim 20-50 \mathrm{~nm}$ diameter $)$ nanoparticles with dilute acid resulted in micropores and mesopores respectively. During the initial formation of the foam, it was observed that different metal nitrates could also result in varied

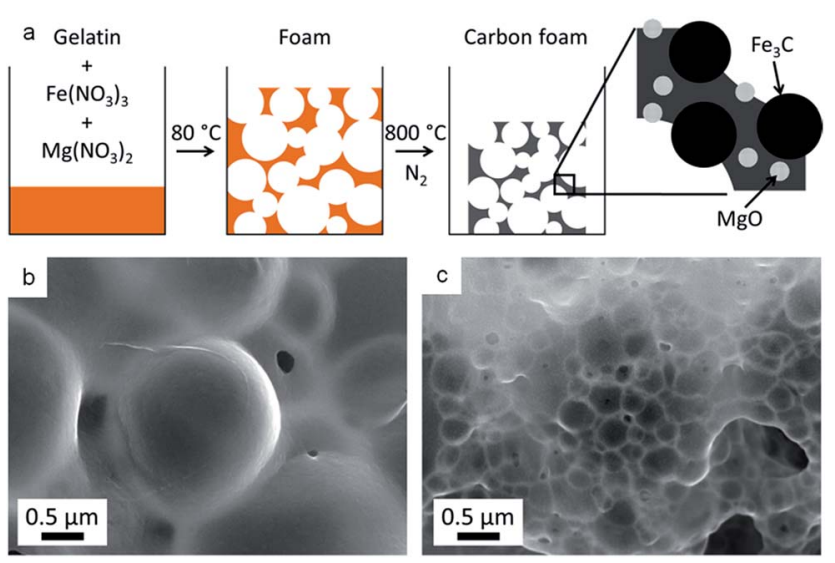

Fig. 1 (a) Schematic showing synthesis of carbon foam containing $\mathrm{MgO}$ and $\mathrm{Fe}_{3} \mathrm{C}$ nanoparticles from a gelatin precursor. Also SEM images showing foams made from (b) $\mathrm{Fe}\left(\mathrm{NO}_{3}\right)_{3} /$ gelatin and (c) $\mathrm{Mg}\left(\mathrm{NO}_{3}\right)_{2} / \mathrm{Fe}\left(\mathrm{NO}_{3}\right)_{3} /$ gelatin (at $75: 25$ molar ratio $\mathrm{Mg}: \mathrm{Fe}$ ). 
foam macrostructures. In addition, mixtures of metal nitrates appeared to act synergistically. An example of this is the combined iron and magnesium nitrates which produce foams with a much smaller cell size than either iron or magnesium individually (Fig. $1 \mathrm{~b}$ and c).

Gelatin foams offer a promising, one-pot route to carbon and ceramic catalysts where the structure and composition are controlled by the choice of metal nitrates used in the precursor. However, to achieve this goal it is important to understand the mechanism of foaming as well as the way metal nitrates influence the foaming process. This paper calls upon a range of techniques including small angle neutron scattering (SANS), rheology, thermogravimetric analysis and circular dichroism to investigate these key factors. By understanding how ionic strength, $\mathrm{pH}$ and metal combinations change gelatin conformation, it will be possible to modify the gel composition to produce carbon and ceramic foams with controlled, multimodal porosity.

\section{Results and discussion}

To examine the effect of different metal nitrates on the foaming of gelatin, a series of samples were prepared using metal nitrates $\mathrm{M}\left(\mathrm{NO}_{3}\right)_{x}$ (where $\mathrm{M}=\mathrm{Na}^{+}, \mathrm{K}^{+}, \mathrm{Mg}^{2+}, \mathrm{Ca}^{2+}, \mathrm{Sr}^{2+}, \mathrm{Fe}^{3+}$, $\mathrm{Cu}^{2+}$ and $\mathrm{Ce}^{3+}$ ). Gelatin (type A) solutions were combined with aqueous metal nitrates at a constant gelatin : metal (mass : moles) ratio. These samples were then heated slowly under nitrogen to determine the temperature of onset of foaming for each metal nitrate. In all cases, the solution initially dried to a sticky resin and then expanded between $70{ }^{\circ} \mathrm{C}$ and $180{ }^{\circ} \mathrm{C}$ to form a brittle, sponge-like structure (Fig. $2 \mathrm{a}$ and $\mathrm{S} 2 \dagger$ ). In contrast, a solution of pure gelatin dries to a brittle, clear film which only begins to expand to produce large cells $(\sim 2 \mathrm{~mm})$ at around $350{ }^{\circ} \mathrm{C}$ (Fig. S1 $\dagger$ ). The foaming onset temperature of gelatin with metal nitrates (Table 1) follows a periodic trend, decreasing from alkali metals to transition metals. Given that the samples were prepared to have a constant ratio of metal ( 0.005 moles) to gelatin $(1 \mathrm{~g})$, it is possible that the different levels of nitrate have an influence. However, $\mathrm{Cu}\left(\mathrm{NO}_{3}\right)_{2}$ and
Table $1 \mathrm{pH}$ for various metal nitrates, as a $10 \% \mathrm{w} / \mathrm{v}$ solution in deionised water and temperature of onset of foaming for resulting mixtures with gelatin

\begin{tabular}{lll}
\hline Solution & pH & $\begin{array}{l}\text { Temperature of } \\
\text { onset of foaming }\left({ }^{\circ} \mathrm{C}\right)\end{array}$ \\
\hline $\mathrm{NaNO}_{3}$ & 6.0 & 180 \\
$\mathrm{KNO}_{3}$ & 6.1 & 160 \\
$\mathrm{Mg}\left(\mathrm{NO}_{3}\right)_{2}$ & 5.2 & 130 \\
$\mathrm{Ca}\left(\mathrm{NO}_{3}\right)_{2}$ & 5.6 & 130 \\
$\mathrm{Sr}\left(\mathrm{NO}_{3}\right)_{2}$ & 5.8 & 150 \\
$\mathrm{Cu}\left(\mathrm{NO}_{3}\right)_{2}$ & 3.5 & 70 \\
$\mathrm{Fe}\left(\mathrm{NO}_{3}\right)_{3}$ & 2.3 & 70 \\
$\mathrm{Ce}\left(\mathrm{NO}_{3}\right)_{3}$ & 4.3 & 130 \\
$\mathrm{HCl}$ & 0.2 & $>200$ \\
$\mathrm{HNO}$ & 0.3 & 70 \\
$\mathrm{TMAN}$ & 5.7 & 160 \\
& &
\end{tabular}

$\mathrm{Ca}\left(\mathrm{NO}_{3}\right)_{2}$ cause foaming at very different temperatures $\left(70{ }^{\circ} \mathrm{C}\right.$ and $130{ }^{\circ} \mathrm{C}$ respectively) despite both being divalent metals.

Another factor that could be influencing the foaming process is $\mathrm{pH}$. Metal nitrate salts hydrolyse in water to form acidic solutions. Table 1 shows that metal nitrate solutions with the lowest $\mathrm{pH}$ drive gelatin foaming at the lowest temperatures. In order to examine this further, gelatin samples were prepared with either nitric or hydrochloric acid. The nitric acid/gelatin sample began foaming at $70{ }^{\circ} \mathrm{C}$ whereas the sample of gelatin and hydrochloric acid dried to a hard film that resisted foaming until heating above $200{ }^{\circ} \mathrm{C}$ in a nitrogen furnace. This demonstrates that the temperature of foaming can be influenced by acidity but the presence of nitrate ions is also important. Tetramethylammonium nitrate (TMAN) was selected as a means of loading the system with nitrate ions without substantially affecting $\mathrm{pH}$ or perturbing the gelatin through interaction with a high charge density cation. The onset temperature of foaming of a mixture of gelatin and TMAN is high $\left(160{ }^{\circ} \mathrm{C}\right)$, supporting the conclusion that both nitrate and a low $\mathrm{pH}$ are important in driving foaming at lower temperatures.

All of the dried metal nitrate/gelatin foams could be calcined under nitrogen to $800{ }^{\circ} \mathrm{C}$ to produce carbon foams (Fig. $2 \mathrm{~b}$ and $\mathrm{S} 3 \dagger$ ). Visual observation of the samples showed that the a

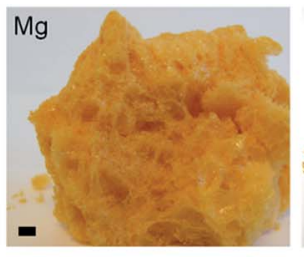

b

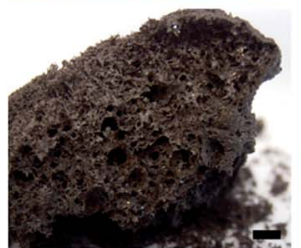

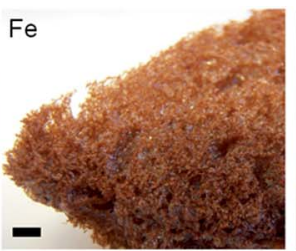
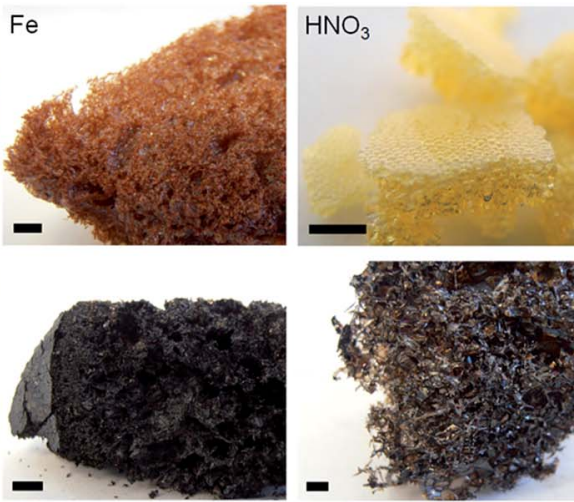
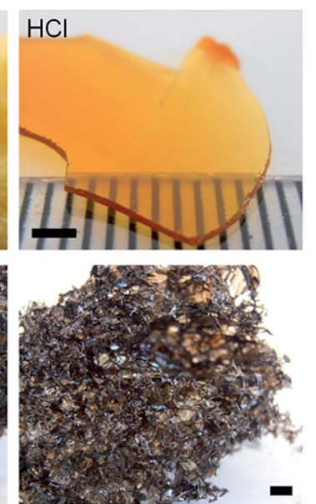

Fig. 2 Images of $\mathrm{Mg}\left(\mathrm{NO}_{3}\right)_{2}$ /gelatin, $\mathrm{Fe}\left(\mathrm{NO}_{3}\right)_{3}$ /gelatin, $\mathrm{HNO}_{3}$ /gelatin, and $\mathrm{HCl} /$ gelatin foams after (a) drying and (b) carbonization at $800{ }^{\circ} \mathrm{C}$ (scale bars $2 \mathrm{~mm}$ ). 
gelatin/ $\mathrm{HCl}$ and gelatin $/ \mathrm{HNO}_{3}$ samples were more open, fragile structures. This is in contrast to the denser foams produced by all metal nitrate/gelatin combinations. This is more clearly shown by scanning electron microscopy (SEM) images (Fig. S4 $\dagger$ ), where metal nitrate/gelatin samples showed a range of open and closed cell foam structures with cells on the order of 1-10 $\mu \mathrm{m}$ in diameter. This illustrates the importance of the metal cation in controlling the macrostructure in these systems.

To determine the cause of foaming in these systems and analyse the gases evolved, samples were studied using thermogravimetric analysis coupled with mass spectrometry. Fig. S5a $\uparrow$ shows mass loss curves for pure gelatin and a sample of gelatin with iron nitrate. Iron nitrate is deliquescent and the main mass loss around $100{ }^{\circ} \mathrm{C}$ for the iron-containing sample can be linked to a large peak in the mass spectrometry data for ions of $\mathrm{m} / \mathrm{z}$ (mass/charge) $=18$, corresponding to water (Fig. S5b $\dagger$ ). For pure gelatin, the main mass loss occurs from around $300{ }^{\circ} \mathrm{C}$. The mass spectrometry data show two major peaks at this point, the first being water $\mathrm{m} / \mathrm{z}=18$ at $\sim 300{ }^{\circ} \mathrm{C}$, indicating dehydration reactions within the gelatin matrix. This is coupled to a major peak for $\mathrm{CO}_{2}(m / z=44)$ supporting the conclusion that this is the main decomposition step for gelatin. The iron-containing sample continues to lose mass above $100{ }^{\circ} \mathrm{C}$, however this is masked by the large percentage mass loss of water. The mass spectrometry data shows a reaction occurring at around $180{ }^{\circ} \mathrm{C}$ involving the release of gas containing ions of $m / z=30$ and 44 . This is significant as these correspond to $\mathrm{NO}$ (nitric oxide) and $\mathrm{N}_{2} \mathrm{O}$ (nitrous oxide) or $\mathrm{CO}_{2}$ respectively, providing evidence that the nitrate oxidises the gelatin. Given the very large contribution made to mass loss by water evaporation, compared to the small loss of nitrogen oxides, it seems likely that the primary mechanism of foaming is the evaporation of water. This is consistent with visual observations of the drying process, as for large samples (deeper gel in the container) foaming appears to start at the top of the sample, before the lower part of the sample is able to dry.
While preparing samples of gelatin with various metal nitrates, it became clear from visual observations that metal salts could significantly influence the properties of the gelatin polypeptide. For example, addition of iron nitrate to a hot aqueous solution of gelatin dramatically increases the viscosity, resulting in a sticky, viscous fluid. Magnesium nitrate has no observable effect but magnesium and iron nitrates together produce a firm, rubbery solid that extrudes solvent. Given that the formation of foams relies both on the production of gas bubbles and the stabilisation of these bubbles, we propose that the main role of the metal in these systems is interaction with the gelatin polymer to change the solution properties, thus offering stability to the resulting foam. A well-established method of probing the gel properties of aqueous gelatin is to measure the gram force required to depress the gel by a defined distance of $20 \mathrm{~mm}$ (where gf is gram-force, a mass of $1 \mathrm{~g}$ multiplied by the standard acceleration due to gravity i.e. $1 \mathrm{gf}=$ $9.8 \mathrm{mN}) \cdot{ }^{13} \mathrm{Fig}$. 3a shows a gel of pure gelatin $(10 \% \mathrm{w} / \mathrm{v}$ in water at $25^{\circ} \mathrm{C}$ ) has a breaking force of $700 \mathrm{gf}$. A series of samples was prepared with the same concentration of gelatin but different concentrations of iron nitrate. Below the breaking point (indicated by a sudden drop in gradient), there is an interesting trend where the gradient initially increases for a small iron concentration, indicating a firmer gel. From $0.005 \mathrm{~mol} \mathrm{~L}^{-1}$ to $0.01 \mathrm{~mol} \mathrm{~L}^{-1} \mathrm{Fe}\left(\mathrm{NO}_{3}\right)_{3}$, the gel also becomes more elastic, indicated by the fact that the breaking point occurs at a much higher load and distance. From $0.025 \mathrm{~mol} \mathrm{~L}^{-1} \mathrm{Fe}\left(\mathrm{NO}_{3}\right)_{3}$, the gelatin gel becomes progressively weaker, demonstrating that iron has a strong effect on the conformation of the gelatin.

Given that gelatin with iron nitrate produces a visual change in viscosity, the rheological properties of this system was also probed using a cone and plate geometry. ${ }^{14}$ The samples were prepared at the maximum possible concentration in order to probe the system as close as possible to the resin-foam transition point (details in ESI $\dagger$ ). Fig. $3 \mathrm{~b}$ shows a plot of the storage and loss moduli for a range of different iron : gelatin ratios. As expected, the storage (or elastic) modulus $\left(G^{\prime}\right)$ is higher than the
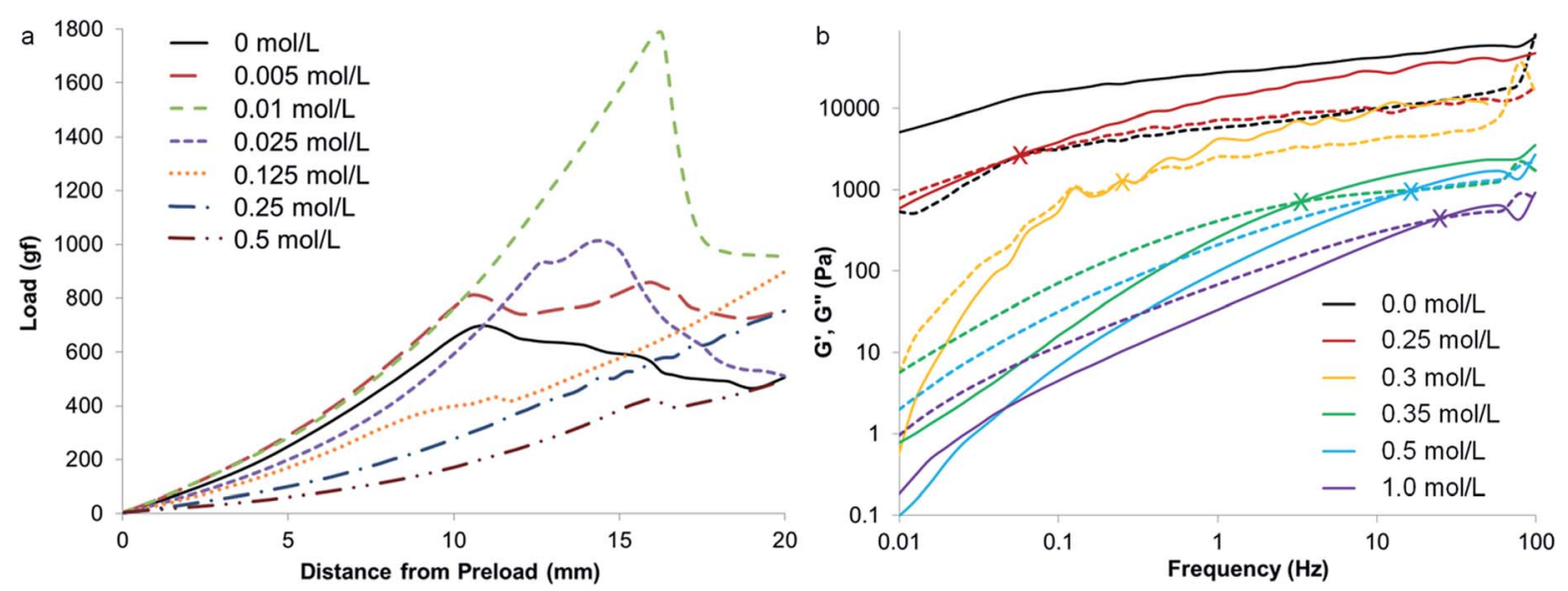

Fig. 3 (a) Load vs. distance plot showing the breaking point for gelatin gels at $10 \% \mathrm{w} / \mathrm{v}$ with different concentrations of iron nitrate. (b) Plots of storage modulus ( $G^{\prime}$, solid lines) and loss modulus $\left(G^{\prime \prime}\right.$, dashed lines) against frequency for gelatin at $20 \%$ w/v with different concentrations of iron nitrate. 
loss modulus $\left(G^{\prime \prime}\right)$ for pure gelatin, indicating a viscoelastic solid at $25{ }^{\circ} \mathrm{C}$. For the samples containing iron, $G^{\prime \prime}$ is higher than $G^{\prime}$ at low frequency, indicating a viscoelastic liquid, as observed physically for samples above $0.25 \mathrm{~mol} \mathrm{~L}^{-1} \mathrm{Fe}\left(\mathrm{NO}_{3}\right)_{3}$. Interestingly, the crossover point (where $G^{\prime}$ becomes higher than $G^{\prime \prime}$, marked by X symbols on the graph) moves to a higher oscillation frequency with increasing iron concentration. This indicates the transition from a viscoelastic liquid to a viscoelastic solid on the time scale of the oscillation (i.e. the samples are able to flow at low frequencies but cannot respond at high frequency). These data follow the trend in visual observations, that increasing concentration of iron appears to transform the gelatin from an elastic gel to a viscous liquid.

Visual observations coupled with studies of physical properties suggest that metal ions interact with the gelatin polymer. The interaction of iron nitrate appears to be particularly strong, exhibited by the increase in viscosity of a gelatin solution on addition of iron nitrate. UV-Vis spectroscopy is one method for studying changes in the coordination environment of coloured metals. Indeed, UV-Vis spectroscopy has previously been used to study the interaction of iron nitrate to gelatin. ${ }^{10}$ There, a series of solutions of constant iron nitrate concentration produced progressively darker red colours on addition of gelatin, which could indicate a different coordination environment of the $\mathrm{Fe}^{3+}$. However, another explanation for this observation could be that gelatin is buffering the acidic iron nitrate solution, driving the hydrolysis of $\left[\mathrm{Fe}\left(\mathrm{H}_{2} \mathrm{O}\right)_{6}\right]^{3+}$ complexes and subsequent formation of dark red iron hydroxo species (eqn (S2) and (S3) $\dagger$ and accompanying text).

Infrared (IR) spectroscopy was also used to probe the binding of metals to gelatin. Fig. S6 $\dagger$ shows the IR spectra for samples of iron nitrate with gelatin, with increasing absorbance in the range $1200-1700 \mathrm{~cm}^{-1}$. A large part of this can be attributed to the presence of nitrate ions in the system, as shown by the increased absorbance of peaks in the $1200-1500 \mathrm{~cm}^{-1}$ range for samples of gelatin with nitric acid (Fig. S7†). The broad bands at $\sim 1625 \mathrm{~cm}^{-1}$ and $1550 \mathrm{~cm}^{-1}$ (corresponding to $\nu_{\mathrm{CO}}$ amide I and $\delta_{\mathrm{NH}}$ amide II $)^{15}$ both shift slightly to lower wavenumbers with increasing concentration of $\mathrm{Fe}\left(\mathrm{NO}_{3}\right)_{3}$ (Fig. S8 $\dagger$ ), which could indicate binding of the $\mathrm{Fe}^{3+}$ to the polypeptide backbone. No such shift is observed in the corresponding peaks for samples of gelatin with $\mathrm{HNO}_{3}$. In order to further investigate the binding of $\mathrm{Fe}^{3+}$ to a polypeptide backbone, polyglycine was used. This is a simple polypeptide of glycine residues and is a reasonable approximation of gelatin, since most gelatins are comprised of $\sim 30 \%$ glycine. Polyglycine is insoluble in water, but after soaking polyglycine powder in iron nitrate solution and repeated rinsing with fresh water, the previously white powder retained an orange colour. This suggests binding of iron to the polyglycine. IR spectra of polyglycine before and after iron soaking (Fig. S9†) support this, as there is a small peak shift in the two main absorption bands, similar to those observed in gelatin.

To examine the effect of metal nitrates on the structure and conformation of the gelatin molecules, small angle neutron scattering (SANS) was used. There are multiple examples of SANS of gelatin under various conditions ${ }^{\mathbf{1 6}}$ and with additives such as surfactants ${ }^{\mathbf{1 7}}$ but, to the best of our knowledge, no studies of the interaction of gelatin with metal nitrates. One of the main features of aqueous gelatin is the sol to gel transition at around $37{ }^{\circ} \mathrm{C}$, driven by the formation of triple helical junction zones through intermolecular interactions. As such, the SANS profiles of gelatin above $\left(60^{\circ} \mathrm{C}\right)$ and below $\left(25^{\circ} \mathrm{C}\right)$ the gel point were obtained as a point of reference. All samples were prepared at $5 \%$ (by weight) gelatin in water, which was the maximum practical concentration, in order to examine the system as close as possible to the resin-foam transition. A plot of scattering intensity $I(Q)$ vs. scattering vector $Q$ for a gelatin sol and gel is shown in Fig. 4. Previous SANS studies of gelatin have attributed large sections of the gelatin gel scattering data to the presence of rod-like triple-helix junction zones. However, given the noted similarity between sol and gel scattering, it appears that the triple helices contribute little to the scattering in this system. At low $Q$, the region of $\sim Q^{-3}$ gradient in both scattering profiles indicates clustering of the gelatin. Previous studies of gelatin gels using USANS have shown that this Porod feature extends well beyond $Q=0.004 \AA^{-1} .^{18}$ This formation of clusters (large, micron size, gel-like structures) is typical of aqueous polymers, particularly polyelectrolytes, and indicates deviation from 'random walk' behaviour.

At intermediate $Q\left(Q \approx 0.03 \AA^{-1}\right)$ there is a turnaround point (Guinier region) which can be used to extract a radius of gyration $\left(R_{\mathrm{g}}\right)$ for the system. ${ }^{19}$ It should be noted that $R_{\mathrm{g}}$ in this case is not the radius of gyration for the whole gelatin polymer, which is much larger and would require data at much lower $Q$ range. Rather, this is the radius of gyration of some other scattering feature related to the correlation length between adjacent chains or the 'mesh size' of the polymer network. The exact values of this $R_{\mathrm{g}}$ should be treated with caution but trends in these numbers can offer useful information about swelling or contraction of the gelatin polymer in different salt conditions. The values of correlation length $(\xi)$ for gelatin in the sol and gel state can also be extracted from the data by fitting with

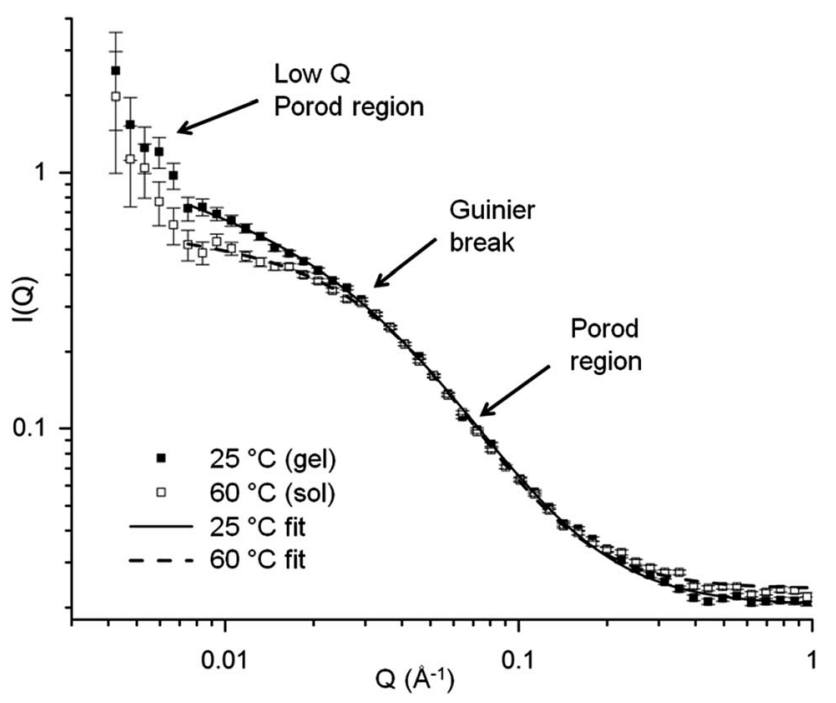

Fig. 4 SANS data for gelatin at $5 \% \mathrm{w} / \mathrm{v}$ concentration in water in the gel $\left(25^{\circ} \mathrm{C}\right)$ and $\mathrm{sol}\left(60^{\circ} \mathrm{C}\right)$ state. 
a modified correlation function (eqn (S1) $\dagger$ and accompanying text). This fit produced values for the correlation lengths of $38 \pm$ $3 \AA$ and $29 \pm 1 \AA$ for the gel and sol respectively, consistent with values found by other studies. ${ }^{20}$

In order to examine the effect of metal nitrates on the structure of gelatin, a series of samples was prepared at constant metal : gelatin ratio $(0.005$ moles to $1 \mathrm{~g}$, equivalent to $0.25 \mathrm{~mol} \mathrm{~L}^{-1}$ metal nitrate). Fig. S10 $\dagger$ shows the scattering data for these samples at both $25{ }^{\circ} \mathrm{C}$ and $60^{\circ} \mathrm{C}$. A simple inspection indicates that while many metal nitrates have an impact on the scattering, the strongest effect by far is that of iron nitrate. This is only significant in the gel state (i.e. at $25{ }^{\circ} \mathrm{C}$ ) as all samples show similar scattering profiles at $60^{\circ} \mathrm{C}$. This could be linked to the fact that $\mathrm{Fe}^{3+}$ is the ion with the highest charge density and so may exhibit stronger interactions with the gelatin. This will be discussed in more detail later.

To further investigate the interaction of iron nitrate with gelatin, a series of samples were prepared with the same concentration of gelatin and varying concentrations of iron nitrate. Fig. 5a shows the trend in scattering for gelatin gels $\left(25^{\circ} \mathrm{C}\right)$ with various concentrations of iron nitrate. Interestingly, the addition of a small amount of iron up to $0.0125 \mathrm{~mol} \mathrm{~L}^{-1}$ initially results in a decrease in scattering intensity for $Q \approx$ $0.007-0.04 \AA^{-1}$. This is coupled to a shift in the Guinier region to higher $Q$ which indicates a reduction in the correlation length. Above $0.0125 \mathrm{~mol} \mathrm{~L}^{-1} \mathrm{Fe}\left(\mathrm{NO}_{3}\right)_{3}$, the Guinier region shifts back to lower $Q$, indicating an increase in correlation length. Analysis of the scattering data for low iron concentration using the modified correlation length model can be used to estimate values for the correlation length as shown in Table 2 . The gelatin polymer has a net negative charge in these conditions ( $\mathrm{pH} 4.7$ at $5 \% \mathrm{w} / \mathrm{v}$ in water). Given that aqueous iron nitrate is strongly acidic, the fall then rise in correlation length may be linked to protonation of the negatively-charged gelatin polymer to first produce a net neutral charge, minimising intramolecular electrostatic repulsions. Continued addition of iron nitrate then results in excess protonation, producing a positively charged polymer and increasing electrostatic repulsions. This contraction and expansion mirrors trends seen in the bloom strength test as detailed above in Fig. 3. Values are also shown for the high- $Q$ Porod exponent and dimensionality factors. The latter gives an indication of structure anisotropy and the low values $(\sim 0)$ indicate isotropic, globular structures as would be expected for a polymer network.

Above iron concentrations of $0.0625 \mathrm{M}$, the Guinier region becomes less apparent and there is a transition to an extended region in which $I(Q)$ scales with $\sim Q^{-2}$. The data sets are not perfectly linear, showing small features that may indicate underlying peaks, suggesting a complex mixture of poorlyresolved scattering features. Taking this and the lack of a clear Guinier region into account the data could not be satisfactorily analysed to obtain a correlation length using the same method
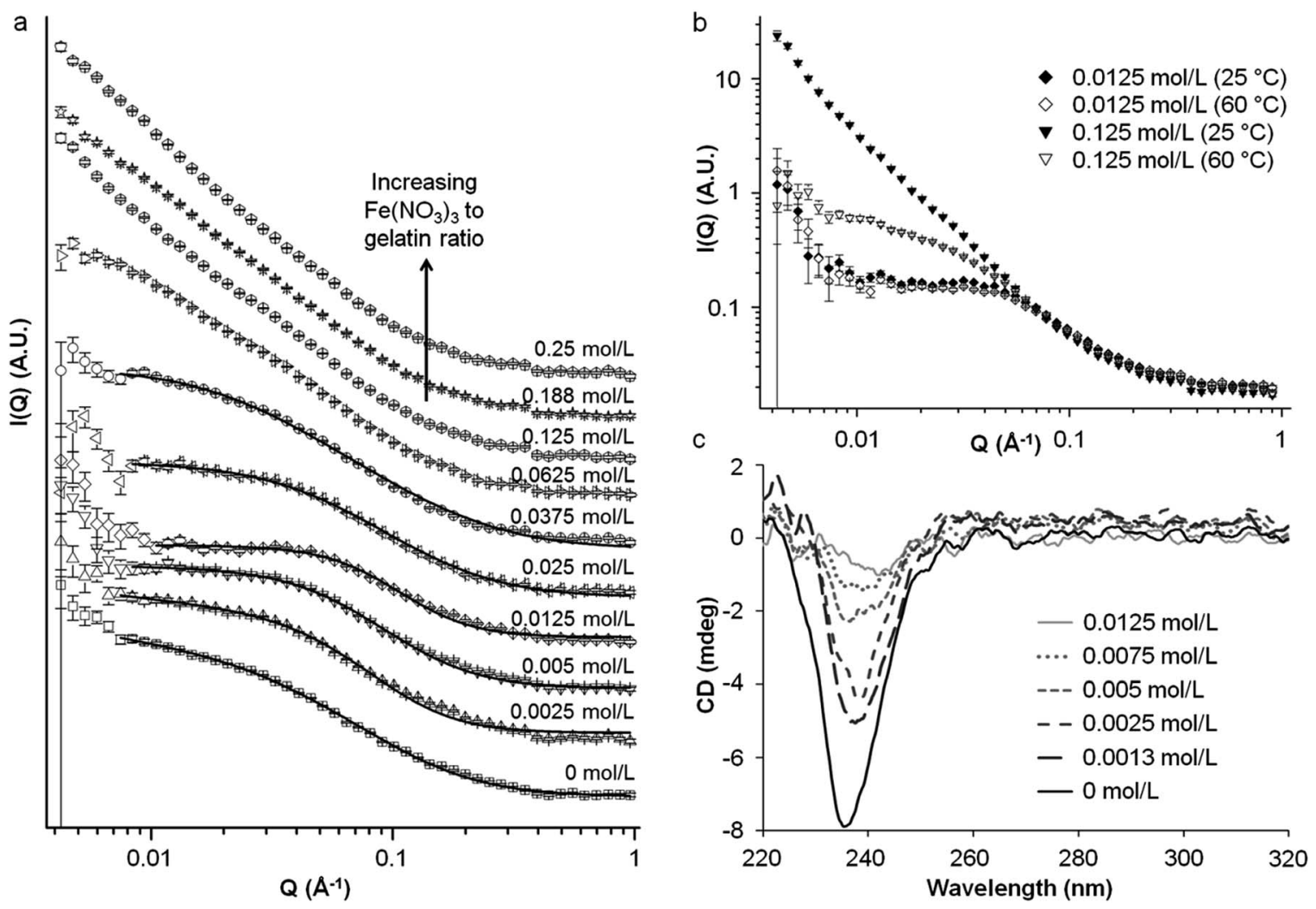

Fig. 5 (a) SANS data for gelatin ( $5 \% \mathrm{w} / \mathrm{v}$ in water) with various concentrations of $\mathrm{Fe}\left(\mathrm{NO}_{3}\right)_{3}$ at $25^{\circ} \mathrm{C}$ and (b) SANS data for two Fe : gelatin ratios at $25^{\circ} \mathrm{C}$ and $60{ }^{\circ} \mathrm{C}$. (c) Circular dichroism data for a series of gelatin ( $1 \% \mathrm{w} / \mathrm{v}$ in water) samples with various concentrations of $\mathrm{Fe}\left(\mathrm{NO}_{3}\right)_{3}$ at $25^{\circ} \mathrm{C}$. Statistical error bars are smaller than the plotting symbols. 
Table 2 Values for the correlation length ( $\xi$ ), high $Q$ Porod exponents and dimensionality factors for gelatin with different concentrations of $\mathrm{Fe}\left(\mathrm{NO}_{3}\right)_{3}$ at $25^{\circ} \mathrm{C}$ and $60{ }^{\circ} \mathrm{C}$. Uncertainties from the fitting process correspond to one standard deviation

\begin{tabular}{lllll}
\hline $\begin{array}{l}\text { Iron conc. } \\
(\mathrm{M})\end{array}$ & $\begin{array}{l}\text { Correlation } \\
\text { length, } \xi(\AA)\end{array}$ & $\begin{array}{l}\text { High } Q \\
\text { Porod } \\
\text { exponent, } \mathrm{m}\end{array}$ & $\begin{array}{l}\text { Dimensionality } \\
\text { factor, s }\end{array}$ & $\begin{array}{l}\text { Chi } \\
\text { squared }\end{array}$ \\
\hline $0^{a}$ & $38 \pm 3$ & $1.9 \pm 0.1$ & $0.07 \pm 0.08$ & 1.7 \\
$0.0025^{a}$ & $28 \pm 1$ & $2.1 \pm 0.1$ & $0.02 \pm 0.00$ & 2.7 \\
$0.005^{a}$ & $20 \pm 1$ & $2.3 \pm 0.1$ & $0.03 \pm 0.00$ & 2.2 \\
$0.0125^{a}$ & $14 \pm 1$ & $2.5 \pm 0.1$ & $0.00 \pm 0.00$ & 2.4 \\
$0.025^{a}$ & $19 \pm 1$ & $2.3 \pm 0.1$ & $0.07 \pm 0.05$ & 1.1 \\
$0.0375^{a}$ & $27 \pm 2$ & $1.9 \pm 0.1$ & $0.35 \pm 0.05$ & 1.8 \\
$0^{b}$ & $29 \pm 1$ & $2.1 \pm 0.1$ & $0.06 \pm 0.00$ & 1.6 \\
$0.0125^{b}$ & $14 \pm 1$ & $2.4 \pm 0.4$ & $0.00 \pm 0.00$ & 2.5 \\
$0.0625^{b}$ & $32 \pm 2$ & $2.0 \pm 0.1$ & $0.01 \pm 0.07$ & 1.3 \\
$0.125^{b}$ & $32 \pm 2$ & $1.9 \pm 0.1$ & $0.11 \pm 0.07$ & 1.3 \\
$0.188^{b}$ & $33 \pm 2$ & $1.9 \pm 0.1$ & $0.08 \pm 0.07$ & 1.2 \\
$0^{b}$ & $38 \pm 3$ & $1.9 \pm 0.1$ & $0.07 \pm 0.08$ & 1.7 \\
${ }^{a}$ Data for samples at $25{ }^{\circ} \mathrm{C}$. & ${ }^{b}$ Data for samples at $60{ }^{\circ} \mathrm{C}$. &
\end{tabular}

as previously described. On the other hand, the extended Porod features in the samples with high iron concentration are consistent with scattering from a fractal network. ${ }^{21}$ In contrast, the scattering profiles for sol samples at $60^{\circ} \mathrm{C}$ (Fig. 5b) maintain a clear Guinier region. The marked difference in scattering between $25^{\circ} \mathrm{C}$ and $60^{\circ} \mathrm{C}$ suggests that a different mechanism of gelation is operating in the high-Fe samples. It has already been noted that addition of small amounts of iron first contracts and then swells the polymer (evidenced by the shift in the Guinier region to lower and then higher $Q$ ). Furthermore, the data from IR spectroscopy as well as experiments with polyglycine suggests that $\mathrm{Fe}^{3+}$ binds to the gelatin backbone. If initial addition of iron nitrate changes the $\mathrm{pH}$ and protonation of the gelatin to swell the chain, it is possible that the binding sites for $\mathrm{Fe}^{3+}$ are made more accessible. At high iron concentrations, the gelation mechanism could then become dominated by $\mathrm{Fe}^{3+}$ crosslinking rather than triple helix formation (Fig. 6). This could explain the very large difference in scattering between $25{ }^{\circ} \mathrm{C}$ and $60{ }^{\circ} \mathrm{C}$ from high-Fe samples. This hypothesis is supported by data from circular dichroism (Fig. 5c), which suggests that addition of iron nitrate to gelatin disrupts triple helix formation, as shown by the disappearance of the peak at $\sim 238 \mathrm{~nm}$.

Scanning electron micrographs of samples prepared from gelatin with combined magnesium and iron nitrates (Fig. 1) above, showed an apparent synergistic effect, producing much smaller cell sizes in the foam than either of the individual metal nitrates. In order to probe this interesting effect, a series of samples were prepared with various molar ratios of $\mathrm{Fe}$ and $\mathrm{Mg}$ nitrates at a constant metal : gelatin ratio. Unfortunately, a full analysis of this system by SANS was impossible as samples prepared with $\mathrm{Fe}: \mathrm{Mg}$ molar ratios of $5: 95,10: 90$ and $25: 75$ all formed hard, rubbery solids that extruded solvent. The samples containing small amounts of iron $\left(0.0025 \mathrm{~mol} \mathrm{~L}^{-1}\right.$ and $0.005 \mathrm{~mol} \mathrm{~L}^{-1}$ equating to $\mathrm{Fe}: \mathrm{Mg}$ molar ratios of $1: 99$ and $2: 98$ respectively) could be prepared as viscous solutions at $60{ }^{\circ} \mathrm{C}$ but the resulting gels were cloudy, indicating light scattering from large structures within the sample. If magnesium nitrate was added first to gelatin, there was no observable effect on colour or viscosity. Subsequent addition of iron nitrate to this mixture then caused formation of a cloudy, rubbery gel, compared to the viscous orange solution formed in the absence of magnesium. This suggests that the presence of magnesium nitrate enhances binding of $\mathrm{Fe}^{3+}$ to the gelatin polymer.

To study the structure of gelatin in the presence of $\mathrm{Mg}$ and $\mathrm{Fe}$ nitrates, SANS was performed on samples of gelatin with iron and magnesium nitrates at molar ratios of $0: 100,1: 99,2: 98$ and $50: 50$. Fig. 7a shows SANS data for samples of gelatin with small amounts of iron nitrate $\left(0.0025 \mathrm{~mol} \mathrm{~L}^{-1}\right.$ and $\left.0.005 \mathrm{~mol} \mathrm{~L}^{-1}\right)$ both with and without magnesium nitrate (equivalent to $1: 99$ and $2: 98$ molar ratios respectively). In addition, a sample was prepared with $0.25 \mathrm{~mol} \mathrm{~L}^{-1} \mathrm{Mg}\left(\mathrm{NO}_{3}\right)_{2}$. The scattering profiles are shown in a constrained $Q$ range for clarity as all of the data is the same above $Q=0.1 \AA^{-1}$. The first point to note is that magnesium nitrate alone appears to have very little effect on the gel structure, as the scattering of the sample with $0.25 \mathrm{~mol} \mathrm{~L}^{-1}$ $\mathrm{Mg}\left(\mathrm{NO}_{3}\right)_{2}$ shows only a small area of slightly increased scattering intensity compared to a gelatin control. This is consistent with visual observations of samples of gelatin with magnesium nitrate which show no change in viscosity or appearance. The second
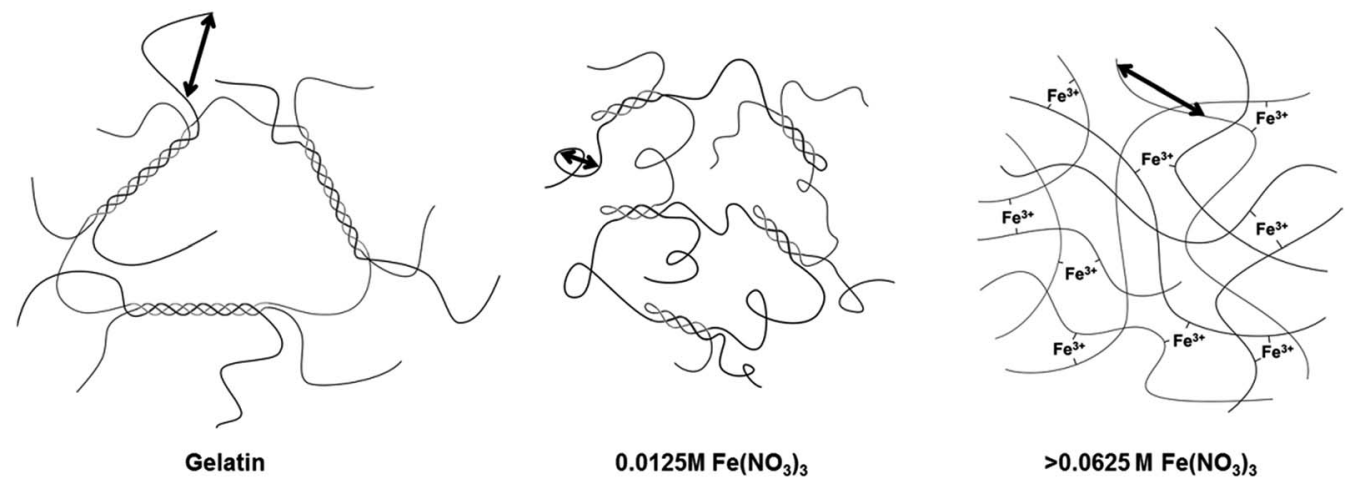

Fig. 6 Schematic showing the proposed structure of the gel at various Fe : gelatin ratios with arrows indicating the correlation length initially decreasing and then increasing as the polymer contracts and then swells. 

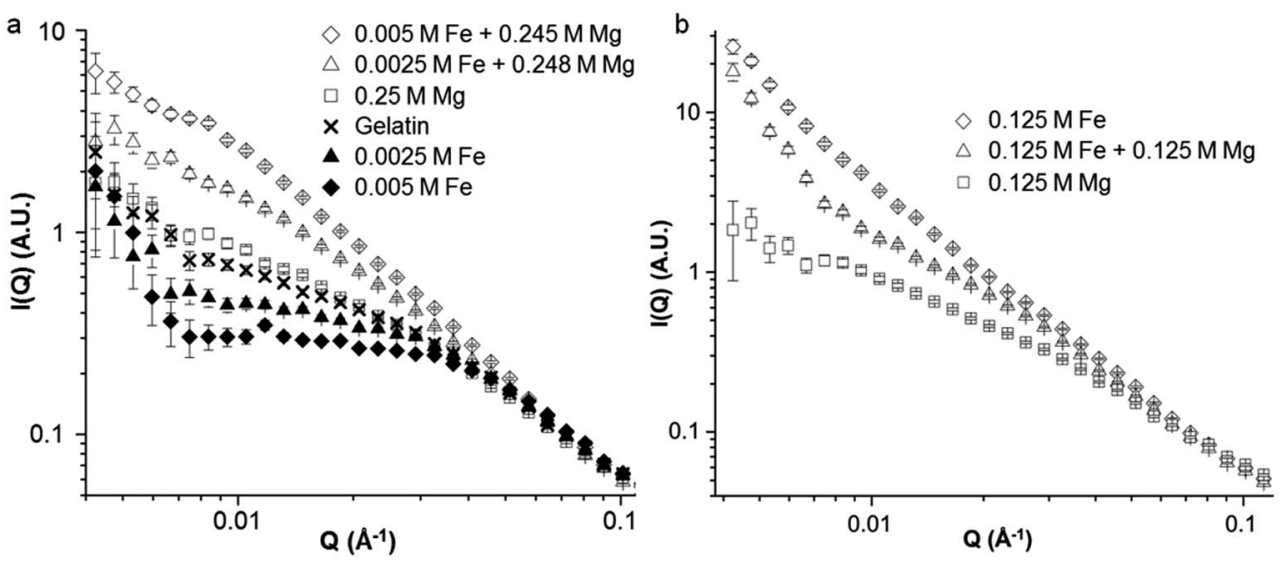

Fig. 7 (a) SANS data for samples of gelatin $(5 \% \mathrm{w} / \mathrm{v})$ at $25^{\circ} \mathrm{C}$ with small amounts of $\mathrm{Fe}\left(\mathrm{NO}_{3}\right)_{3}$, both with and without $\mathrm{Mg}\left(\mathrm{NO}_{3}\right)_{2}($ equating to molar ratios of 1 : 99 and 2 : 98). (b) SANS data for samples of gelatin at $25^{\circ} \mathrm{C}$ with Fe(NO$)_{3}$ or $\mathrm{Mg}\left(\mathrm{NO}_{3}\right)_{2}$ at 0.125 mol L $\mathrm{L}^{-1}$ as well as a sample with both $\mathrm{Mg}$ and Fe nitrates at $0.125 \mathrm{~mol} \mathrm{~L}^{-1}$.

point is that samples with $0.0025 \mathrm{~mol} \mathrm{~L}^{-1}$ and $0.005 \mathrm{~mol} \mathrm{~L}^{-1}$ iron nitrate show very different scattering profiles when magnesium nitrate is present compared to the corresponding samples with no magnesium. The samples of iron and magnesium nitrates together show scattering profiles primarily comprised of a single long Porod region, indicating a fractal structure. The fact that $\mathrm{Mg}\left(\mathrm{NO}_{3}\right)_{2}$ alone has very little effect on the scattering profile suggests that the high intensity seen in the mixed Fe/Mg samples is due to a synergistic effect of the $\mathrm{Mg}$ and $\mathrm{Fe}$, consistent with visual observations. The equivalent data for samples at $60{ }^{\circ} \mathrm{C}$ is shown in Fig. S11. $\dagger$ For samples containing $0.0025 \mathrm{~mol} \mathrm{~L}^{-1}$ and $0.005 \mathrm{~mol} \mathrm{~L}^{-1}$ iron nitrate, there is an increase in scattering intensity at low $Q$ on moving from $60^{\circ} \mathrm{C}$ to $25^{\circ} \mathrm{C}$. This increased intensity is presumably due to structural changes occurring during the sol-gel transition. For the sample containing only $\mathrm{Mg}\left(\mathrm{NO}_{3}\right)_{2}$, there is negligible difference in scattering between the sol and the gel. This supports the hypothesis that while magnesium nitrate has little apparent effect on gelatin structure and gelation, it changes the way that $\mathrm{Fe}^{3+}$ binds to the gelatin.

The effect of magnesium on the binding of iron to gelatin is also observed at higher $\mathrm{Fe}: \mathrm{Mg}$ ratios. Fig. 7b shows SANS profiles for samples of gelatin with $0.125 \mathrm{~mol} \mathrm{~L}^{-1} \mathrm{Fe}\left(\mathrm{NO}_{3}\right)_{3}$ or $0.125 \mathrm{Mg}\left(\mathrm{NO}_{3}\right)_{2}$ as well as $0.125 \mathrm{~mol} \mathrm{~L}^{-1} \mathrm{Fe}\left(\mathrm{NO}_{3}\right)_{3}$ and $\mathrm{Mg}\left(\mathrm{NO}_{3}\right)_{2}$ together. Again, if scattering intensity was purely linked to ionic strength, it would be expected that the sample with both Fe and $\mathrm{Mg}$ nitrates would show the highest scattering intensity. Instead, the data interestingly seems to show features of both the separate Fe-only and Mg-only systems. The mixed Fe/Mg nitrate system shows a Guinier region at $Q \approx 0.04 \AA^{-1}$, from which a correlation length can be estimated. There is then a Porod region of sharp gradient at low $Q$, indicating a mass fractal structure. The shift of the Guinier region to lower $Q$ when going from only $0.125 \mathrm{~mol} \mathrm{~L}^{-1} \mathrm{Mg}\left(\mathrm{NO}_{3}\right)_{2}$ to $0.125 \mathrm{~mol} \mathrm{~L}^{-1}$ $\mathrm{Mg}\left(\mathrm{NO}_{3}\right)_{2}$ and $\mathrm{Fe}\left(\mathrm{NO}_{3}\right)_{3}$ together indicates a larger correlation length. The Porod region with a large slope $\left(\sim \mathrm{Q}^{-3}\right)$ at $Q \approx$ 0.004-0.01 $\AA^{-1}$ then suggests the presence of an extended fractal network. The lack of this feature in the scattering data for the sample at $60{ }^{\circ} \mathrm{C}$ (Fig. S12 $\dagger$ ) shows that this is a gel network formed on cooling.

From these data, we can conclude that the magnesium acts to change the binding properties of iron to gelatin. As discussed, this is not simply due to ionic strength as magnesium alone does not significantly affect the visual appearance or scattering profile of the gelatin. Neither is it an effect simply of $\mathrm{pH}$ or nitrate concentration, as otherwise samples of combined iron and magnesium nitrates would show similar scattering profiles to those of $0.25 \mathrm{~mol} \mathrm{~L}^{-1}$ iron nitrate. As described above, the combination of iron and magnesium nitrates can be observed at certain molar ratios to produce a cloudy precipitate (1: 99 and $2: 98 \mathrm{Fe}: \mathrm{Mg}$ ) or a rubbery solid (5:95 and $25: 75$ $\mathrm{Fe}: \mathrm{Mg}$ ). This could be an example of 'salting out', a common phenomenon in proteins, where ions can increase or decrease the solubility of proteins in water (Hofmeister effect). ${ }^{22}$ In this case, it seems likely that the $\mathrm{Mg}^{2+}$ ions change the solution conformation of the gelatin molecules in order that $\mathrm{Fe}^{3+}$ ions can bind more strongly. This could be due to direct interaction of $\mathrm{Mg}^{2+}$ with the gelatin or the effect of $\mathrm{Mg}^{2+}$ on the water molecules and hydrogen bonding around the gelatin.

\section{Conclusions}

In conclusion, carbon foams can be prepared by heating gelatin with metal nitrates under inert atmospheres. The temperature of spontaneous foaming occurs between $70{ }^{\circ} \mathrm{C}$ and $180{ }^{\circ} \mathrm{C}$ depending on the metal and appears to be driven primarily by evaporation of water rather than nitrate oxidation of the gelatin polymer, although the presence of nitrate as well as a low $\mathrm{pH}$ is required for foaming. Analysis of the physical properties of gelatin shows a clear weakening of the gel structure and transition from a gel to a viscoelastic liquid on addition of iron nitrate. This is mirrored in visual observations, where iron nitrate has a strong effect on the gelatin viscosity compared to no apparent effect on addition of other metal nitrates. Small angle neutron scattering shows a similar strong effect of iron nitrate on gelatin, in particular a large increase in scattering 
intensity for a $0.25 \mathrm{~mol} \mathrm{~L}^{-1} \mathrm{Fe}\left(\mathrm{NO}_{3}\right)_{3}$ concentration compared to gelatin in water. Observation of an initial drop in scattering intensity and shift of the Guinier region to higher $Q$ on addition of iron suggests contraction and then swelling of the gelatin. This is proposed to be due to the acidic iron nitrate protonating the negatively-charged gelatin polymer, changing the structure from triple-helical junction zones to a network of gelatin molecules crosslinked by $\mathrm{Fe}^{3+}$. Visual observations and neutron scattering data both indicate that $\mathrm{Mg}^{2+}$ enhances the binding of $\mathrm{Fe}^{3+}$ to gelatin, to form either cloudy precipitates or rubbery solids. This is proposed to be an example of the Hofmeister effect, where the $\mathrm{Mg}^{2+}$ and $\mathrm{Fe}^{3+}$ ions act together to 'salt out' the gelatin. Interestingly, the combination of iron and magnesium nitrates that produce the smallest foam cell size (25: 75 molar ratio) is also that which has the strongest change in appearance on preparation, transforming the gelatin solution into a rubbery solid. From all these observations, it appears that metal nitrates change the structure of gelatin foams by modifying the viscoelastic properties of the polymer through changing conformation and also binding to the polypeptide backbone. This ability to balance aqueous precursors to control the macrostructure of a porous carbon is an exciting approach and there is a lot of scope to explore other combinations of metal salts and $\mathrm{pH}$ conditions as well as other types of gelatin and alternative biopolymers.

\section{Acknowledgements}

The authors acknowledge the STFC for beam time on SANS2D (Experiment No. RB1520385) and EPSRC and EU (Marie Curie "SusNano") for funding. The identification of commercial products does not imply endorsement by the National Institute of Standards and Technology nor does it imply that these are the best for the purpose. The SANS part of this work is based upon activities supported in part by the US National Science Foundation under Agreement No. DMR-1508249.

\section{References}

1 N. D. Petkovich and A. Stein, Chem. Soc. Rev., 2013, 42, 37213739.

2 C. M. A. Parlett, K. Wilson and A. F. Lee, Chem. Soc. Rev., 2013, 42, 3876-3893.
3 H. Wang, L. Zhang, Z. Chen, J. Hu, S. Li, Z. Wang, J. Liu and X. Wang, Chem. Soc. Rev., 2014, 43, 5234-5244.

4 S. Sotiropoulou, Y. Sierra-Sastre, S. S. Mark and C. A. Batt, Chem. Mater., 2008, 20, 821-834.

5 Y. Ofir, B. Samanta and V. M. Rotello, Chem. Soc. Rev., 2008, 37, 1814-1825.

6 A. E. Danks, S. R. Hall and Z. Schnepp, Mater. Horiz., 2016, 3, 91-112.

7 I. Braccini and S. Pérez, Biomacromolecules, 2001, 2, 10891096.

8 Z. Schnepp, S. C. Wimbush, S. Mann and S. R. Hall, $A d v$. Mater., 2008, 20, 1782-1786.

9 Z. Schnepp, S. C. Wimbush, S. Mann and S. R. Hall, CrystEngComm, 2010, 12, 1410-1415.

10 Z. Schnepp, M. Thomas, S. Glatzel, K. Schlichte, R. Palkovits and C. Giordano, J. Mater. Chem., 2011, 21, 17760-17764.

11 Z. Schnepp, M. J. Hollamby, M. Tanaka, Y. Matsushita, Y. Xu and Y. Sakka, Chem. Commun., 2014, 50, 5364-5366.

12 Z. Schnepp, Y. Zhang, M. J. Hollamby, B. R. Pauw, M. Tanaka, Y. Matsushita and Y. Sakka, J. Mater. Chem. A, 2013, 1, 13576-13581.

13 O. T. Bloom, US Pat. 1540979 A, 1925.

14 M. Djabourov, J. Leblond and P. Papon, J. Phys., 1988, 49, 319-332.

15 N. Benbettaïeb, M. Kurek, S. Bornaz and F. Debeaufort, J. Sci. Food Agric., 2014, 94, 2409-2419.

16 I. Pezron, M. Djabourov and J. Leblond, Polymer, 1991, 32, 3201-3210.

17 T. Cosgrove, S. J. White, A. Zarbakhsh, R. K. Heenan and A. M. Howe, J. Chem. Soc., Faraday Trans., 1996, 92, 595-599.

18 M. Helminger, B. Wu, T. Kollmann, D. Benke, D. Schwahn, V. Pipich, D. Faivre, D. Zahn and H. Cölfen, Adv. Funct. Mater., 2014, 24, 3187-3196.

19 F. Horkay and B. Hammouda, Colloid Polym. Sci., 2008, 286, 611-620.

20 F. Carn, F. Boué, M. Djabourov, N. Steunou, T. Coradin, J. Livage, S. Floquet, E. Cadot and E. Buhler, Soft Matter, 2012, 8, 2930-2944.

21 B. Hammouda, Probing Nanoscale Structures - The SANS Toolbox, 2016, ch. 54, http://www.ncnr.nist.gov/staff/ hammouda/the_sans_toolbox.pdf.

22 F. Hofmeister, Arch. Exp. Pathol. Pharmakol., 1888, 24, 247260. 